\title{
Heat stress responses and thermotolerance
}

\begin{abstract}
The rising ambient temperature by plant cells is crucial for the timely activation of various molecular defences before the appearance of heat damage. The heat-threshold level varies considerably at different developmental stages. With a view to survive under heat stress, mechanisms of regulation at the molecular level enable plants to prosper. Traditional breeding contributed for improving heat tolerance meagrely. The genetic transformation approach needs to be accelerated that can mitigate harmful effects by developing improved thermotolerance of crop plants. In this background, a thorough understanding of physiological responses of plants to high temperature, mechanisms of heat tolerance and possible strategies is vital. Temperature changes are sensed through cellular responses due to signal transduction into the cell. A key ingredient for plants temperature sensing ability is a specialized histone protein, dubbed H2A.Z that wraps DNA into a more tightly packed structure. Further, metabolic reactions and internal conductance to $\mathrm{CO}_{2}$ decrease Rubisco activation, inhibition of Rubisco activase and subsequently slowing down net photosynthesis (Pn). Importance of internal conductance to $\mathrm{CO}_{2}$, heat inducible transcription factor for heat shock response (HSR) involve different HSR genes. The mechanisms, which are regulated at the molecular level, facilitate plants to thrive under heat stress. Exogenous applications of protectants such as osmoprotectants, phytohormones, signaling molecules, trace elements etc. have shown beneficial effects on plants growing under high temperature, due to the growth promoting and antioxidant activities of these compounds. There is acute necessity of crop biotechnology research for evolving genetically modified (GM) crops for a high $\mathrm{CO}_{2}$ world at this juncture. So, attaining thermotolerance is a lively process to escape damages caused by heat stress.
\end{abstract}

Keywords: heat-stress threshold, thermostability, heat sensing by plants, thermotolerance
Volume I Issue 3 - 2014

\author{
A Hemantaranjan,' A Nishant Bhanu, ${ }^{2} \mathrm{MN}$ \\ Singh, ${ }^{2}$ DK Yadav,' PK Patel, ${ }^{3}$ Radha Singh,' \\ Deepmala Katiyar' \\ 'Department of Plant Physiology, Banaras Hindu University, India \\ ${ }^{2}$ Department of Genetics and Plant Breeding, Banaras Hindu \\ University, India \\ ${ }^{3}$ Indian Institute of Vegetable Research, India
}

Correspondence: A Hemantaranjan, Department of Plant Physiology, Banaras Hindu University, Institute of Agricultural Sciences, Varanasi-22 1005, Uttar Pradesh, India, Tel +05426702939,Email hemantaranjan@gmail.com

Received: May 01, 2014 | Published: July 07, 2014
Abbreviations: Pn, photosynthesis; HSR, heat shock response; GM, genetically modified; ROS, reactive oxygen species; MTS, membrane thermal stability; $H S F \mathrm{~s}$, heat stress transcription factors; RuBP, ribulose-1,5-bisphosphate; RuBP, ribulose bisphosphate; Chl, chlorophyll; Pchlide, protochlorophyllide; LEA, late embryogenesis abundant; CAT, catalase; $A P X$, ascorbate peroxidase; SOD, superoxide dismutase; POX, peroxidase; GR, glutathione reductase; GST, glutathione s-transferase; CDPKs, ca-dependent protein kinases; MAPK/MPKs, mitogen-activated protein kinase; ABA, abscisic acid; FLU, fluridone; JA, jasmonic acid; 4-EBL, 24-epibrassinolide; HSGs, heat shock genes; $A P X 1$, ascorbate peroxidase gene; HSE, heat shock element; HS, heat shock; Hsf: heat shock transcription factor; GUS, $\beta$-glucuronidase; miRNAs, microRNAs; HSPs, heat shock proteins

\section{Introduction}

Future global climate change, with predicted $1.5-5.8^{\circ} \mathrm{C}$ increases in temperatures by 2100 has to cause heat stress to create threats to agricultural production. ${ }^{1}$ An increase in global temperature ranging from 1.1 to $6.4^{\circ} \mathrm{C}$ depending on global emissions scenarios, will accompany the rises in atmospheric $\mathrm{CO}_{2}$. Though high temperature and other abiotic stresses are clearly limiting factors for crops cultivated on marginal lands, crop productivity far and wide is often at the mercy of random environmental fluctuations. Existing assumption about global climate change is that most agricultural regions will experience additional extreme environmental fluctuations. ${ }^{2}$ Direct injuries due to high temperatures include protein denaturation and aggregation and increased fluidity of membrane lipids. Indirect or slower heat injuries include inactivation of enzymes in chloroplast and mitochondria, inhibition of protein synthesis, protein degradation and loss of membrane integrity. ${ }^{3}$ Heat stress also affects the organization of microtubules by splitting and/or elongation of spindles, formation of microtubule asters in mitotic cells and elongation of phragmoplast microtubules. $^{4}$

The unfavourable effects of heat stress can be mitigated by developing crop plants with improved thermotolerance using an assortment of genetic approaches. For this reason, a thorough understanding of physiological responses of plants to high temperature, mechanisms of heat tolerance and possible strategies for improving crop thermotolerance is crucial. Acquiring thermotolerance is a lively progression by which considerable amounts of plant resources are diverted to structural and functional maintenance to escape damages caused by heat stress. Although biochemical and molecular aspects of thermotolerance in plants are relatively well understood, additional studies focused on phenotypic flexibility and assimilate partitioning under heat stress and factors modulating crop heat tolerance are imperative. High temperature during seed germination may slow down or totally inhibit germination, depending on plant species and the intensity of the stress. ${ }^{5}$ At later stages, high temperature may adversely affect vital physiological processes like photosynthesis, respiration, water relations and membrane stability and also modulate levels of hormones and primary and secondary metabolites. Furthermore, for the duration of plant ontogeny, enhanced expression of a variety of heat shock proteins, other stress-related proteins and production of reactive oxygen species (ROS) constitute major plant responses to heat stress. Such studies combined with genetic approaches to identify 
and map genes (or QTLs) conferring thermotolerance will facilitate marker-assisted breeding for heat tolerance and paving the way for cloning and characterization of underlying genetic factors which could be useful for engineering plants with improved heat tolerance.

The changes in temperature might induce cellular responses indicating that temperature is perceived and the temperature signal is transduced into the cell. While the signaling pathways triggered temperature changes, the way plants sense temperature is often considered as hard to pin down. Plants have no inner thermometer as such; however, adjustments in cellular equilibriums triggered by temperature changes act as networked thermostats to sense heat and cold. Amongst these temperature-sensitive devices, membrane fluidity, protein conformation, cytoskeleton depolymerization and metabolic reactions were identified. ${ }^{6}$

Temperature variations play a role in the reset of internal clocks and diurnal synchronization. ${ }^{7}$ For certain species, exposure to a low temperature is necessary to trigger developmental processes such as flowering ${ }^{8}$ or germination. ${ }^{9}$ Temperature changes are perceived and then transduced to the nucleus where the transcriptome is altered. ${ }^{10}$ Nevertheless, advancement has been made on temperature sensing, especially on heat sensing, as heat is a physical parameter that influences molecular (protein, DNA) or supramolecular (membranes, chromosomes) structures through simple thermodynamic effects.

Breeding for selecting genotypes with increased heat tolerance is therefore, one of the most vital objectives in crop improvement programme. This review accentuates briefly on plant responses to heat stress at the whole plant elucidating, in general, the sensing of high temperature by plants providing physiological and molecular grounds, viz., heat stress threshold, cell membrane thermostability, effects on metabolic reactions and internal conductance to $\mathrm{CO}_{2}$; impairment of chlorophyll biosynthetic reactions; thermotolerance mechanisms; finally highlighting crop biotechnology in global climate change.

\section{Heat sensing by plants}

Science daily in 2013 September brought into light the 2010 report of Kumar et al., ${ }^{11}$ that plants are incredibly temperature sensitive and can perceive changes of as little as one degree Celsius. Plants 'feel' the temperature rise and coordinate an appropriate response by activating hundreds of genes and deactivating others as per the DNA is packaged. Specialized histone protein is a key ingredient for plants temperature sensing ability that was evolved by means of the model plant Arabidopsis thaliana. The dubbed H2A.Z wraps DNA into a strongly packed structure known as a nucleosome where with rise of temperature H2A.Z histones allows DNA to progressively unwrap directing nucleosomes to loosen up. As argued by researchers, the basic discovery could ultimately establish to have vital implications for world food security. ${ }^{11}$ However, Saidi et al., ${ }^{12}$ were of the opinion that when temperature elevates, the heat signal is probably transduced by several pathways for coming together into the final activation of $H S F \mathrm{~s}$, the expression of HSPs and the onset of cellular thermotolerance.

\section{Heat-stress threshold}

Heat stress is often defined as a period in which temperatures are hot enough for a sufficient period of time to cause irreversible damage to plant function or development. Plants can be damaged by either high day or high night temperatures and by either high air or soil temperatures. A plant's temperature usually runs just above the air temperature. A threshold temperature refers to a value of daily mean temperature at which a detectable reduction in growth begins. Knowledge of lower threshold temperatures is important in physiological research as well as for crop production. Base threshold temperatures vary with plant species. For other plant species, the higher threshold temperature may be lower or higher than $35^{\circ} \mathrm{C}$. High temperature sensitivity is particularly important in tropical and subtropical climates as heat stress may become a major limiting factor for field crop production. About $90 \%$ of the water that enters a plant's roots is used for cooling under warm dry conditions. The amount of water lost by a plant depends on its size, the intensity of the surrounding light, temperature, humidity and wind speed. All of which influence evaporative demand. Brief exposure of plants to high temperatures during seed filling can accelerate senescence, diminish seed set and seed weight and reduce yield..$^{13}$ In addition, heat stress problems also make the plant susceptible to pests and other environmental problems.

The threshold maximum seed zone temperature for emergence of cowpea is around $37^{\circ} \mathrm{C}$ compared with 25 to $33^{\circ} \mathrm{C}$ for lettuce, for example. High day temperatures can cause harm to components of leaf photosynthesis by reducing carbon dioxide assimilation rates. A perception of photosynthesis to heat is largely due to damage to photosystem II constituents positioned in the thylakoid membranes of the chloroplast and membrane belongings. Membrane thermostability has been evaluated by measuring electrolyte leakage from leaf disks subjected to extreme temperatures. ${ }^{14}$ Additionally stable membranes exhibit slower electrolyte leakage.

Critical studies comparing responses of extreme temperatures reveal premature death of plants. Agriculturally important grain legume crop field pea is very sensitive to high day temperatures with death of the plant occurring when air temperatures exceed about $35^{\circ} \mathrm{C}$ for sufficient duration, whereas barley is very heat tolerant, especially during grain filling. Reproductive development of many crop species is damaged by heat such that they produce no flowers or if they produce flowers they may set no fruit or seeds. The damaging effects of heat stress on reproductive development for cowpea, common bean, tomato, cotton, rice, wheat, maize and sorghum have discussed comprehensively. ${ }^{15,16}$ In case of wheat, the threshold temperature is $26^{\circ} \mathrm{C}$ at the post-anthesis stage. ${ }^{17}$

\section{Cell membrane thermostability}

Sustained function of cellular membranes under stress is pivotal for processes such as photosynthesis and respiration. ${ }^{14}$ Physiological and biochemical screening techniques as a complement to empirical breeding methods could increase selection efficiency. The genes securing heat tolerance may be lost in the breeding programs which rely mainly on only empirical selection. Membrane thermal stability (MTS) can be a significant selection criterion for heat stress tolerance. MTS is determined by measuring of electrical conductivity of aqua use phase in which leaf tissue exposure to high temperature. Membrane stability parameters of genotypes decreased during the later developmental stages. Genetic variation among genotypes for membrane stability can be utilized in wheat breeding in heat-stressed environments.

The integrity and functions of biological membranes are sensitive to high temperature, as heat stress alters the tertiary and quaternary structures of membrane proteins enhancing the permeability of membranes evident from increased loss of electrolytes. Membranes 
are moving mosaics of proteins and lipids. Lipids stagger between monolayers, diffuse within the plane of a monolayer and rotate about their own axes, with their acyl chains also rotating around $\mathrm{C}-\mathrm{C}$ bonds. Much of the heat sensing occurred through protein unfolding. Since protein conformation changes with temperature, both temperature downshift and temperature up shift can lead to protein unfolding. ${ }^{18}$ Yamada et al., ${ }^{19}$ evinced that heat-induced protein denaturation could participate to the activation of some heat stress transcription factors $(H S F \mathrm{~s})$. Eukaryotic $H S F \mathrm{~s}$ have a central role in heat induced transcriptome remodelling through their binding to the heat stress elements of promoters. ${ }^{20}$ Upon heat exposure, HSP90 is inactivated and this would probably lead to At HSFAld being activated and inducing heat-responsive genes. ${ }^{19}$

Heat stress also leads to the oligomerization of a thioredoxin and a thioredoxin-like protein from Arabidopsis, and this oligomerization correlates with them switching from a disulfide reductase activity to molecular chaperone activity. ${ }^{21,22}$ FAD8, the Arabidopsis $\omega-3$ fatty acid desaturase, has a $\mathrm{C}$-terminal region determining its instability when shifted from $22^{\circ} \mathrm{C}$ to $27^{\circ} \mathrm{C}$. A characteristic of the heat response is less lipid desaturation, so FAD8 destabilization can be considered as a perception event that directly occurs on response effectors. ${ }^{23}$ A temperature shift from $27^{\circ} \mathrm{C}$ to $42^{\circ} \mathrm{C}$ resulted in the disruption of the majority of microtubules in tobacco cells after $30 \mathrm{~min}$, as in Arabidopsis roots shifted from $20^{\circ} \mathrm{C}$ to $42^{\circ} \mathrm{C} .4^{4,24}$

\section{Metabolic reactions and internal conductance to $\mathrm{CO}_{2}$ \\ Photosynthesis}

Cell metabolism is influenced by temperature effects on enzyme activities. Changes may generate signaling pathways triggering heat/ cold responses. This is illustrated here by temperature-sensitive photosynthesis related processes. Ribulose-1,5-bisphosphate (RuBP) carboxylase/oxygenase (Rubisco) catalyzes the first step in net photosynthetic $\mathrm{CO}_{2}$ assimilation and photorespiratory carbon oxidation. The enzyme is notoriously inefficient as a catalyst for the carboxylation of RuBP and is subject to competitive inhibition by $\mathrm{O}_{2}$, inactivation by loss of carbamylation and dead-end inhibition by RuBP. These insufficiencies make Rubisco rate limiting for photosynthesis and an obvious target for increasing agricultural productivity. The regeneration of $\mathrm{Pi}$ is necessary for optimal carbon fixation. At low temperatures, all the metabolic reactions, including those of sucrose synthesis, are slower, ${ }^{25}$ while phosphorylated intermediates accumulate, $\mathrm{Pi}$ is not released. ${ }^{26-28}$ limiting Ribulose Bisphosphate $(\mathrm{RuBP})$ regeneration and photosynthesis, ${ }^{25,29,30}$ the limitation can be overcome by supplementing cells with phosphate. ${ }^{31,32}$ Phosphate depletion is a signal and some genes induced by low temperatures are also induced by depletion in phosphate. ${ }^{33}$

Ribulose-1,5-bisphosphate carboxylase/oxygenase (Rubisco; EC 4.1.1.39) activase mRNA and protein synthesis were measured in the leaves of cotton (Gossypium hirsutum L.) plants under control $\left(28^{\circ} \mathrm{C}\right)$ or heat-stress $\left(41^{\circ} \mathrm{C}\right)$ conditions. In response to high temperature, de novo protein synthesis quickly shifted from mostly expression of Rubisco large and small subunits to the major heat-shock proteins, while de novo synthesis of the constitutively expressed 47- and 43$\mathrm{kDa}$ activase polypeptides was not appreciably altered. However, a $46-\mathrm{kDa}$ cross-reacting polypeptide was also present in heat-stressed plants and constituted about $5 \%$ of the total activase after $48 \mathrm{~h}$ at high temperature. The identity of the heat-induced 46-kDa polypeptide as activase was confirmed by protein sequencing, which showed that its N-terminal sequence was identical to that of the constitutive 47$\mathrm{kDa}$ activase polypeptide. The presence of multiple isoforms for both the 47-and $43-\mathrm{kDa}$ activase polypeptides on immunoblots of twodimensional gels and the complex banding pattern on Southern blots together suggest the resolution of more than one activase gene and the possibility that the synthesis of the heat-induced activase polypeptide may be regulated transcriptionally. Induction of a new form of activase may constitute a mechanism of photosynthetic acclimation to heat stress in cotton. ${ }^{34}$

Heat stress inhibits photosynthesis. ${ }^{25,29,30,35,36}$ Inhibition of net photosynthesis $(\mathrm{Pn})$ by moderate heat stress has been attributed to an inability of Rubisco activase to maintain Rubisco in an active form. The temperature optimum of Rubisco activation was $10^{\circ} \mathrm{C}$ higher in the creosote bush (Larrea tridentata) compared with the Antarctic hairgrass (Deschampsia antarctica), resembling the temperature response of $\mathrm{Pn}$, which increased markedly with increasing internal $\mathrm{CO}_{2}$ concentration subjected to moderate heat stress even under nonphotorespiratory conditions. Nonphotochemical quenching of chlorophyll fluorescence, the effective quantum yield of photochemical energy conversion (Delta $\left.\mathrm{F} / \mathrm{F}(\mathrm{m}){ }^{\prime}\right)$ and the maximum yield of PSII $[\mathrm{F}(\mathrm{v}) / \mathrm{F}(\mathrm{m})]$ were more sensitive to temperature in Antarctic hairgrass and two other species endemic to cold regions [i.e. Lysipomia pumila and spinach (Spinacea oleracea)] compared with creosote bush and three species [i.e. jojoba (Simmondsia chinensis), tobacco (Nicotiana tabacum) and cotton (Gossypium hirsutum)] from warm regions.

\section{Internal conductance to $\mathrm{CO}_{2}$}

Internal conductance to $\mathrm{CO}_{2}$ transfer from intercellular spaces to chloroplasts poses a major limitation to photosynthesis, but only three studies have investigated the temperature dependence. Based on chloroplast $\mathrm{CO}_{2}$ concentration, neither maximum rates of carboxylation nor RuBP-limited rate of electron transport peaked between $10^{\circ} \mathrm{C}$ and $35^{\circ} \mathrm{C}$. Both were described well by an Arrhenius function and had similar activation energies $(57-70 \mathrm{~kJ} \mathrm{~mol}(-1)) .{ }^{37}$

\section{Heat stress-in duced impairment of chlorophyll biosynthetic reactions}

When plants are uncovered to low- or high-temperature stress, Chl biosynthesis is affected. ${ }^{38,39}$ Biosynthesis of porphyrins and particularly that of Chl during early greening stages of seedlings has been elucidated in detail. ${ }^{40-48}$ Chlorophyll (Chl) biosynthesis in chill $\left(7^{\circ} \mathrm{C}\right)$-and heat $\left(42^{\circ} \mathrm{C}\right)$-stressed cucumber $($ Cucumis sativus $\mathrm{L}$. cv poinsette) seedlings was affected by 90 and $60 \%$, respectively. Inhibition of Chl biosynthesis was partly due to impairment of 5aminolevulinic acid biosynthesis both in chill- (78\%) and heat-stress (70\%) conditions. Protochlorophyllide (Pchlide) synthesis in chilland heat-stressed seedlings was inhibited by 90 and $70 \%$, respectively.

In heat-stressed seedlings, although $\delta$-aminolevulinic acid dehydratase and porphobilinogen deaminase were partially inhibited, one of the porphyrinogen-oxidizing enzymes, uroporphyrinogen decarboxylase, was stimulated and coproporphyrinogen oxidase and protoporphyrinogen oxidase were not substantially affected, which demonstrated that protoporphyrin IX synthesis was relatively more resistant to heat stress. Protochlorophyllide (PChlide) oxidoreductase, which is responsible for phototransformation of PChlide to chlorophyllide, increased in heat-stress conditions by 
$46 \%$ over that of the control seedlings, whereas it was not affected in chill-stressed seedlings. In wheat (Triticum aestivum L. cv HD2329) seedlings porphobilinogen deaminase, PChlide synthesis and PChlide oxidoreductase were affected similar to that of cucumber, suggesting that temperature stress has a broadly similar effect on $\mathrm{Chl}$ biosynthetic enzymes in both cucumber and wheat. ${ }^{49}$

\section{Mechanisms of thermotolerance}

Plant scientists involved in research on high temperature stress are endeavouring to discover the plant responses that lead to high temperature and they are also trying to investigate how plants can be managed in high temperature environments. Recent widely studied molecular approaches have included omics techniques and the development of transgenic plants through manipulation of target genes. ${ }^{50-52}$ Such underlying molecular processes may provide ways to develop stress tolerant varieties and to grow agriculturally important crop plants under heat stress. Heat stress differentially affects the stability of various proteins, membranes, RNA species and cytoskeleton structures and alters the efficiency of enzymatic reactions in the cell for which the major physiological processes obstacle and creates metabolic imbalance. ${ }^{53-55}$ Different metabolic pathways are depended upon enzymes which are sensitive to various degrees of high temperature. It has been suggested that, like other abiotic stress, heat stress might uncouple enzymes and metabolic pathways which cause the accumulation of unwanted and harmful ROS most commonly singlet oxygen $\left(1 \mathrm{O}_{2}\right)$, superoxide radical $\left(\mathrm{O}_{2} \cdot-\right)$, hydrogen peroxide $\left(\mathrm{H}_{2} \mathrm{O}_{2}\right)$ and hydroxyl radical $(\mathrm{OH} \cdot)$ which are responsible for oxidative stress. ${ }^{56}$ The reaction centres of PSI and PSII in chloroplasts are the major sites of ROS generation though ROS are also generated in other organelles viz. peroxisomes and mitochondria. ${ }^{57} \mathrm{~A}$ linear relationship exists between maximal efficiency of PSII and the accumulated ROS.

Heat tolerance is the ability of the plant to grow and produce economic yield under high temperature. Plants have evolved various mechanisms for flourishing under higher prevailing temperatures. They include short term avoidance/acclimation mechanism or long term evolutionary adaptations. Some major tolerance mechanisms, including ion transporters, late embryogenesis abundant (LEA) proteins, osmoprotectants, antioxidant defense and factors involved in signaling cascades and transcriptional control are essentially significant to counteract the stress effects. ${ }^{58,59}$ The stress responsive mechanism is established by an initial stress signal that may be in the form of ionic and osmotic effect or changes in the membrane fluidity. This helps to re-establish homeostasis and to protect and repair damaged proteins and membranes. ${ }^{60}$

Activities of different antioxidant enzymes are temperature sensitive and activation occurs at different temperature ranges but the activities of these enzymes increase with increasing temperature. Chakrabortty et al., ${ }^{61}$ observed that catalase (CAT), ascorbate peroxidase $(A P X)$ and superoxide dismutase (SOD) showed an initial increase before declining at $50^{\circ} \mathrm{C}$, while peroxidase (POX) and glutathione reductase (GR) activities declined at all temperatures ranging from 20 to $50^{\circ} \mathrm{C}$. In addition, total antioxidant activity was at a maximum at $35-40^{\circ} \mathrm{C}$ in the tolerant varieties and at $30^{\circ} \mathrm{C}$ in the susceptible ones. Their activities also differ depending upon tolerance or susceptibility of different crop varieties, their growth stages and growing season. ${ }^{61,62}$

The activity of the enzymes glutathione S-transferase (GST), ascorbate peroxidase $(A P X)$ and catalase (CAT) was more enhanced in the cultivar showed better tolerance to heat stress and projection against ROS production. They reported that the tolerance of the wheat varieties appeared to be correlated with the antioxidant level, though changes in activity were observed for different antioxidant enzymes. Antioxidant defense mechanism plays an important role in the heat stress tolerance of wheat genotypes and it was observed that the activities of SOD, APX, CAT, GR and POX increased significantly at all stages of growth in heat tolerant cultivers (C 306) in response to heat stress treatment, while susceptible cultivar (PBW 343) showed a significant reduction in CAT, GR and POX activities in the heat tolerance treatment. Further, to create response in specific cellular compartments or tissues against a certain stimuli, interaction of cofactors and signaling molecules are required. Signaling molecules are involved in activation of stress responsive genes. Various signal transduction molecules related to stress responsive gene activation are depending upon plant type, types of stresses. Some broad group of those are the $\mathrm{Ca}$-dependent protein kinases (CDPKs), Mitogenactivated protein kinase (MAPK/MPKs), NO, sugar (as signaling molecule), phytohormones. $^{63}$ These molecules together with transcriptional factors activate stress responsive genes.

In recent decades, exogenous application of protectant such as osmoprotectants, phytohormones, signaling molecules, trace elements, etc., have shown beneficial effect on plants grown under heat tolerance as these protectants has growth promoting and antioxidant capacity. ${ }^{64-67}$ Accumulation of osmolytes such as proline, glycine betaine and trehalose is a well-known adaptive mechanism in plants against abiotic stress conditions including heat tolerance. Since heat sensitive plants apparently lack the ability to accumulate these substances, heat tolerance in such plants can be improved by exogenous application of osmoprotectants. ${ }^{2,68,69}$ Proline and glycine betaine application considerably reduced the $\mathrm{H}_{2} \mathrm{O}_{2}$ production, improved the accumulation of soluble sugars and protected the developing tissues from heat stress effects. However, Pro was more effective than glycine betaine in that study. Exogenous proline and glycine betaine application also improved the $\mathrm{K}^{+}$and $\mathrm{Ca}_{2}^{+}$contents, and increased the concentrations of free proline, glycine betaine and soluble sugars which rendered the buds more tolerant to heat tolerance. Identically, exogenous applications of several phytohormones were found to be effective in mitigating heat stress in plants. Chhabra et al., ${ }^{70}$ studied the phytohormones induced amelioration of heat tolerance stress in Brassica juncea and found that soaking seeds in $100 \mu \mathrm{M}$ IAA, $100 \mu \mathrm{M}$ GA, 50 and $100 \mu \mathrm{M}$ Kinetin and 0.5 and $1 \mu \mathrm{M}$ ABA were effective for mitigating the effect of heat stress $(47 \pm 0.5$ $\left.{ }^{\circ} \mathrm{C}\right)$. The significant observation was that both growth promoting and growth retarding hormones were effective in mitigation of heat stress effects. The role of growth promoting hormone in the mitigation of heat stress was at a concentration which was otherwise lethal or toxic to its growth seedling stage. Salicylic acid is a plant hormone found to be an effective protectant under heat stress.

The oxidative damages in abscisic acid (ABA) treated plants were also much lower than non-treated plants under heat stress condition which was indicated by reduced MDA and $\mathrm{H}_{2} \mathrm{O}_{2}$ contents. In the contrary, inhibitor of ABA biosynthesis, fluridone (FLU) reverted the actions induced by ABA which suggest a clear role of ABA in mitigating heat-induced damages. Chen et al., ${ }^{71}$ treated grape seedlings with $50 \mu \mathrm{M}$ jasmonic acid (JA) solution and observed that that JA could extenuate the change of stress under heat stress $\left(42^{\circ} \mathrm{C}\right)$. This protection was accompanied by the upregulation of antioxidant enzyme's (SOD, CAT and POD) activity compared with these 
untreated under heat stress. Kumar et al., ${ }^{11}$ investigated the effect of different concentrations of 24-epibrassinolide (24-EBL) on growth, antioxidant enzyme of mustard (B. juncea) seedlings. Polyamine provides protection to plant from high temperature stress in different ways. They can affect photosynthesis in different ways. Structure and function of the photosynthetic apparatus can be regulated effectively by PAs. Polyamines are able to maintain thermostability of thylakoid membranes under heat thus increase photosynthetic efficiency. ${ }^{72,73}$

The up-regulation of several heat inducible genes, commonly referred as "heat shock genes" (HSGs) which encode HSPs and these active products are very much necessary for plant's survival under fatal high temperature. ${ }^{74}$ High temperature induced constitutive expression of most of these proteins protect intracellular proteins from being denaturation and preserve their stability and function through protein folding; thus it acts as chaperones. ${ }^{75}$ The HSPs are extremely heterogeneous in nature and this dynamic protein family is expanding continuously as per the recent researches are going on Over expression of plant HSFs can increase plant's thermo-tolerance, but gene knockouts of individual HSFs tested so far have had little effect on survival at high temperature. In plants, there are a number of non-HSP transcripts that are upregulated by heat. ${ }^{76}$ In particular, the Arabidopsis cytosolic ascorbate peroxidase gene $(A P X 1)$ has been shown not only to be heat upregulated, but also to contain a functional heat shock element (HSE) in its 5'-promoter region. As heat stress tolerance is a polygenic trait (controlled by different sets of genes), various different components of tolerance are critical at different developmental stages or in different tissues of plant; hence, it shows spacio-temporal mechanism and regulation. ${ }^{77}$ Thus, the use of genetic stocks with different degrees of heat tolerance, correlation and cosegregation analyses, molecular biology techniques and molecular markers to identify tolerance QTLs are promising approaches to dissect the genetic basis of plant's thermotolerance. ${ }^{78}$

\section{Heat-inducible transcription factor}

The heat shock response (HSR), defined as a transient reprogramming of gene expression, is a conserved biological reaction of cells and organisms to elevated temperatures. ${ }^{52}$ HSR has been of great interest for studying molecular mechanisms of stress tolerance and regulation of gene expression in plants. The temperature for the induction of HSR coincides with optimum growth temperature for any given species, which is normally $5-10^{\circ} \mathrm{C}$ above normothermic conditions. The kinds of this response include induction of HSPs and subsequently acquisition of a higher level of thermotolerance. The transient synthesis of HSPs suggests that the signal triggering the response is lost, inactivated or no longer recognized under conditions of long-term heat treatment. ${ }^{79}$ The involvement of HSPs in heat-stress tolerance is a logical model, but direct support for function of HSPs in promoting thermotolerance has been difficult to obtain. ${ }^{79,80}$ Eukaryotic cells respond to elevated temperature or heat shock (HS) by inducing the transcription of genes encoding proteins such as molecular chaperones. Many of these proteins are involved in preventing or repairing the damage caused by heat stress and thus confer increased thermotolerance. ${ }^{81,82}$ This phenomenon, known as HS response (HSR), is initiated by the activation of the HS transcription factor $(H s f)$, a conserved protein present in all eukaryotic organisms studied to date..$^{83,84}$

In the last decade, two research groups independently reported the function of $H s f A 2$ by characterizing the same Arabidopsis T-DNA knockout line. The disruption of $H s f A 2$ caused a slight reduction in expression of some Hsp genes upon HS treatment and that the knockout mutant displayed reduced basal and AT as well as oxidative stress tolerance, while overexpression of $H_{s} f A 2$ enhances tolerance under these stress conditions. ${ }^{85}$ Schramm et al. ${ }^{86}$ identified a subset of genes whose expression was reduced upon HS treatment in the knockout mutant. They showed that $H s f A 2$ bound to the promoter regions of selected target genes and activated a $\beta$-glucuronidase (GUS) reporter that was fused to them. According to the transcriptome studies, six $H_{s f}$ genes, $H_{s f A 2}, H_{s f \mathrm{~A}} 4 \mathrm{a}, H_{s f \mathrm{~A}} 7 \mathrm{a}, H_{s f} \mathrm{~B} 1, H_{s f} \mathrm{~B} 2 \mathrm{a}$ and $H_{s f} \mathrm{~B} 2 \mathrm{~b}$, are significantly up-regulated in Arabidopsis leaves by HS treatment $\left(37^{\circ} \mathrm{C}\right.$ for $\left.1 \mathrm{~h}\right)$. This result is comparable to microarray data except that of Arabidopsis sample (ecotype Columbia [Col-0] 5-dold seedlings), HsfA $7 \mathrm{~b}$ but not $H s f \mathrm{~A} 4 \mathrm{a}$ was significantly responsive to heat. From the HSR microarray data available to date, HsfA2 is the gene most induced by heat, which suggests a dominant role for the gene in sustaining the HSR, a role that cannot be replaced by $H s f \mathrm{~A} 7 \mathrm{a}$ and $H s f A 7 \mathrm{~b}{ }^{87}$

\section{"Omics" technologies}

The "omics" technologies have provided novel opportunities and expectations for the identification of transcriptional, translational and post-translational mechanisms and signaling pathways that regulate the plant response(s) to abiotic stress including high temperature. ${ }^{88,89}$ DNA is the starting point of all molecular evidences related to heat stress tolerance in plants and contains several heat stress responsive genes in their genome (genomics). A large number of genes with potential roles in heat stress responses have been identified using genetic screens and genome wide expression studies. Transcriptory products (mRNAs), from such genes in the genome, have made their transcriptome (transcriptomics) and then proteome (proteomics) when they translate into the functional proteins (responsible for stress tolerance). In response to developmental and environmental cues, plants employ a post-transcriptional regulation of gene expression by non-protein coding small RNAs or microRNAs (miRNAs). ${ }^{90}$ Overexpression of miRNA-resistant target genes will help to overcome post-transcriptional gene silencing, and thus may lead to better expression of engineered trait in transgenic plants. Understanding the roles of small RNAs in transcriptome homeostasis, cellular tolerance, phenological and developmental plasticity of plants under heat stress and recovery will help genetic engineering of stress tolerance in crop plants. ${ }^{90}$ In addition, microarray technology has recently become a powerful tool for the systematic analysis of expression (or transcriptome) profiles of large numbers of genes those are induced or repressed by heat treatment. ${ }^{91,92}$ Recent microarray studies in Arabidopsis deficient with APX gene, however, have found that certain HSPs are expressed typically under other stress conditions, although expression of HSPs under heat stress occurs normally. ${ }^{93}$

\section{Crop biotechnology in global climate change}

Advances in the understanding of crop-environment interactions at the molecular, biochemical, physiological, and agronomic scales, as well as their relevance to biotechnological crop improvement, have been extensively reviewed. An entire range of research tools is encompassed by Biotechnology that scientists use to comprehend, apply and thereby influence the genetic make-up of organisms for use in agriculture, crops, forestry, livestock and fisheries. Genetically modified crops have the ability to grow faster with development time being reduced from years to months as compared to that of 
traditional breeding. ${ }^{94}$ Other benefits include increase in crop yields, improvement in breeding insects, pest, disease and weather resistant as well as herbicides tolerant crops. However, genetically modified technology has faced many critics and has equally enjoyed the support of fanatics and thus, sparked many debates across the globe. New crop cultivars will be required for a changing climate characterised by increased summer drought and heat stress all over the world. However, the uncertainty in climate predictions poses a challenge to crop scientists and breeders who have limited time and resources and must select the most appropriate traits for improvement. Modelling is a powerful tool to quantify future threats to crops and hence identify targets for improvement. Scientists have used a wheat simulation model combined with local-scale climate scenarios to predict impacts of heat stress and drought on winter wheat in Europe. Despite the lower summer precipitation projected for 2050s across Europe, relative yield losses from drought is predicted to be smaller in the future, because wheat will mature earlier avoiding severe drought. ${ }^{95}$

The wheat yield could be limited by the grain number and the grain size, which are established to a large extent at the period around anthesis (flowering), a stage in development known to be sensitive to high temperature stress. ${ }^{96}$ A modelling study for the main wheat growing regions of Australia demonstrated that variations in average growing-season temperatures of $2^{\circ} \mathrm{C}$ can cause reductions in grain production of up to $50 \%$, most of which can be attributed to increased leaf senescence as a result of high temperatures. Another study in the USA demonstrated that nonlinear temperature effects on grain yields, which show a steep yield decline after temperature exceeds cropspecific thresholds, could lead to severe damages to U.S. corn and soybeans yields under climate change. ${ }^{97}$ If the crop is unstressed, it establishes the grain number and its potential size at sufficiently large values to accommodate biomass produced during grain filling. In this case, the yield is effectively source-limited..$^{98}$ The grain number and the grain size can be substantially reduced if a cultivar, sensitive to heat stress, is exposed to a short period of high temperature around flowering, limiting the capacity of grains to store newly produced biomass. In this case, grain growth becomes a sink-limited process. In an experiment on the combine effects of $\mathrm{CO}_{2}$ and temperature on the grain yield, Mitchell et al., ${ }^{99}$ observed that a temperature of $27^{\circ} \mathrm{C}$ or higher applied mid-way through anthesis could result in a high number of sterile grains and considerable yield losses. Wheeler et al. ${ }^{100}$ used a temperature gradient tunnel system to demonstrate that at $30^{\circ} \mathrm{C}$ or elevated prior to anthesis significantly reduced the grain number and, subsequently, yield. Crop yields are predicted to decrease approximately $10 \%$ for every one-degree increase in temperature. Wheat cultivation spread to a wider range of climatic conditions, but a positive association between temperature and precipitation remained. Drought, extreme temperatures, flooding and soil quality have challenged agriculture since its inception.

\section{Acknowledgements}

None.

\section{Conflict of interest}

The author declares no conflict of interest.

\section{References}

1. Rosenzweig C, Iglesias A, Yang XB, et al. Climate change and extreme weather events. Implications for food production, plant diseases and pests. Global Change and Human Health. 2001;2(2):90-104.
2. Jain R, Solomon S, Shrivastava AK, et al. Nutrient application improves stubble bud sprouting under low temperature conditions in sugarcane. Sug Tech. 2001;11(1):83-85

3. Howarth CJ, Ashraf M, Harris PJC. Genetic improvements of tolerance to high temperature. In: Ashraf M, et al. editors. Abiotic stresses: plant resistance through breeding and molecular approaches. New York, USA: Haworth Press Inc; 2005. p. 277-300.

4. Smertenko A, Draber P, Viklicky V, et al. Heat stress affects the organization of microtubules and cell division in Nicotiana tabacum cells. Plant Cell Environ. 1997;20(12):1534-1542.

5. Wahid A, Gelani S, Ashraf M, et al. Heat tolerance in plants:An overview. Environmental and Experimental Botany. 2007;61(3):199-223.

6. Ruelland E, Zachowski A. How plants sense temperature. Environmental and Experimental Botany. 2010;69(3):225-232.

7. Thines B, Harmon FG. Ambient temperature response establishes ELF3 as a required component of the core Arabidopsis circadian clock. Proc Natl Acad Sci U S A. 2010;107(7):3257-3262.

8. Kim DH, Doyle MR, Sung S, et al. Vernalization:winter and the timing of flowering in plants. Annu Rev Cell Dev Biol. 2009;25:277-299.

9. Finch-Savage WE, Leubner-Metzger G. Seed dormancy and the control of germination. New Phytol. 2006;171(3):501-523.

10. Zeller G, Henz SR, Widmer CK, et al. Stress-induced changes in the Arabidopsis thaliana transcriptome analyzed using whole-genome tiling arrays. Plant J. 2009;58(6):1068-1082.

11. Kumar S, Sirhindi G, Bhardwaj R, et al. Role of 24-epibrassinolide in amelioration of high temperature stress through antioxidant defense system in Brassica juncea L. Plant Stress. 2012;6(1):55-58.

12. Saidi Y, Finka A, Goloubinoff P. Heat perception and signalling in plants:a tortuous path to thermotolerance. New Phytol. 2011;190(3):556-565.

13. Siddique KHM, Loss SP, Regan KL, et al. Adaptation and seed yield of cool season grain legumes in Mediterranean environments of south-western Australia. Aust J Agric Res. 1999;50(3):375-388.

14. Blum A. Plant Breeding for Stress Environments. Boca Raton, Florida: CRC Press Inc; 1988. 223 p.

15. Hall AE. Breeding for heat tolerance. Plant Breed Rev. 1992;10:129168.

16. Hall AE. Physiology and breeding for heat tolerance in cowpea, and comparison with other crops. pp. 271-284, In: CG Kuo edito. Adaptation of Food Crops to Temperature and Water Stress. Publ. No. 93-410, Taiwan:" Asian Vegetable Research and Development Center, Shanhua; 1993.

17. Stone PJ, Nicolas ME. Wheat cultivars vary widely in their responses of grain yield and quality to short periods of post-anthesis heat stress. Aust J Plant Physiol. 1994;21(6):887-900.

18. Pastore A, Martin SR, Politou A, et al. Unbiased cold denaturation:lowand high-temperature unfolding of yeast frataxin under physiological conditions. J Am Chem Soc. 2007;129(17):5374-5375.

19. Yamada K, Fukao Y, Hayashi M, et al. Cytosolic HSP90 regulated the heat shock response that is responsible for heat acclimation in Arabidopsis thaliana. J Biol Chem. 2007;282(52):37794-37804.

20. von Koskull-Doring P, Scharf KD, Nover L. The diversity of plant heat stress transcription factors. Trends Plant Sci. 2007;12(10):452-457.

21. Lee JR, Lee SS, Jang HH, Lee YM, et al. Heat-shock dependent oligomeric status alters the function of a plant-specific thioredoxin-like protein, AtTDX. Proc Natl Acad Sci U S A. 2009;106(14):5978-5983. 
22. Park SY, Fung P, Nishimura N, et al. Abscisic acid inhibits type $2 \mathrm{C}$ protein phosphatases via the PYR/PYL family of START proteins. Science. 2009;324(5930):1068-1071.

23. Matsuda O, Sakamoto H, Hashimoto T, et al. A temperature-sensitive mechanism that regulates post-translational stability of a plastidial omega-3 fatty acid desaturase (FAD8) in Arabidopsis leaf tissues. J Biol Chem. 2005;280(5):3597-3604.

24. Muller J, Menzel D, Samaj J. Cell-type-specific disruption and recovery of the cytoskeleton in Arabidopsis thaliana epidermal root cells upon heat shock stress. Protoplasma. 2007;230(3-4):231-242.

25. Sage RF, Kubien DS. The temperature response of C3 and C4 photosynthesis. Plant Cell Environ. 2007;30(9):1086-1106.

26. Labate CA, Adcock MD, Leegood RC. Effects of temperature on the regulation of photosynthetic carbon assimilation in leaves of maize and barley. Planta. 1990;181(4):547-554.

27. Cen YP, Sage RF. The regulation of Rubisco activity in response to variation in temperature and atmospheric $\mathrm{CO}_{2}$ partial pressure in sweet potato Plant Physiol. 2005;139(2):979-990.

28. Savitch LV, Gray GR, Huner NPA. Feedback-limited photosynthesis and regulation of sucrose-starch accumulation during cold acclimation and low temperature stress in a spring and winter wheat. Planta. 1997;201(1):18-26.

29. Yamori W, von Caemmerer S. Effect of Rubisco activase deficiency on the temperature response of $\mathrm{CO}_{2}$ assimilation rate and Rubisco activation state:insights from transgenic tobacco with reduced amounts of Rubisco activase. Plant Physiol. 2007;151(4):2073-2082.

30. Yamori W, Ko N, Kouki H, et al. Phenotypic plasticity in photosynthetic temperature acclimation among crop species with different cold tolerances. Plant Physiol. 2010;152(1):388-399.

31. Leegood RC, Furbank RT. Stimulation of photosynthesis by $2 \%$ oxygen at low temperatures is restored by phosphate. Plant. 1986;168(1):84-93.

32. Hendrickson L, Chow WS, Furbank RT. Low temperature effects on grapevine photosynthesis:the role of inorganic phosphate. Funct Plant Biol. 2004;31(8):789-801.

33. Zhao L, Liu F, Xu W, et al. Increased expression of OsSPX1 enhances cold/subfreezing tolerance in tobacco and Arabidopsis thaliana. Plant Biotechnol J. 2009;7(6):550-561.

34. Law RD, Crafts-Brandner SJ, Salvucci ME. Heat stress induces the synthesis of a new form of ribulose-1,5-bisphosphate carboxylase/oxygenase activase in cotton leaves. Planta. 2001;214(1):117-125.

35. Zhang R, Sharkey TD. Photosynthetic electron transport and proton flux under moderate heat stress. Photosynth Res. 2009;100(1):29-43.

36. Salvucci ME. Association of Rubisco activase with chaperonin-60beta:a possible mechanism for protecting photosynthesis during heat stress. $J$ Exp Bot. 2008;59(7):1923-1933.

37. Warren CR. Does growth temperature affect the temperature responses of photosynthesis and internal conductance to $\mathrm{CO}_{2}$ ? A test with Eucalyptus regnans. Tree Physiol. 2008;28(1):11-19.

38. Van Hasselt PR, Strikwerda JT. Pigment degradation in discs of the thermophilic Cucumis sativus as affected by light, temperature, sugar application and inhibitors. Plant Physiol. 1976;37(4):253-257.

39. Feierabend J. Capacity for chlorophyll synthesis in heat-bleached $70 \mathrm{~S}$ ribosome-deficient rye leaves. Planta. 1977;135(1):83-88.

40. Tripathy BC, Rebeiz CA. Chloroplast biogenesis:demonstration of monovinyl and divinyl monocarboxylic routes of chlorophyll biosynthesis in higher plants. J Biol Chem. 1986;261(29):13556-13564.
41. Tripathy BC, Rebeiz CA. Non-equivalence of glutamic and 5-aminolevulinic acids as substrates for protochlorophyllide and chlorophyll biosynthesis in darkness. In:J Biggins editor. Progress in Photosynthesis Research. Vol 4. Boston, MA: Nijhoff Publishers; 1987. p. 439-443.

42. Tripathy BC, Rebeiz CA. Chloroplast biogenesis 601:conversion of divinyl protochlorophyllide to monovinyl protochlorophyllide in green(ing) barley, a dark monovinyl/light divinyl plant species. Plant Physiol. 1988;87:89-94.

43. Hukmani P, Tripathy BC. Spectrofluorometric estimation of intermediates of chlorophyll biosynthesis:protoporphyrin IX, Mg-protoporphyrin, and protochlorophyllide. Anal Biochem. 1992;206(1):125-130.

44. Hukmani P, Tripathy BC. Chlorophyll biosynthetic reactions during senescence of excised barley (Hordeum vulgare L. cv IB 65) leaves. Plant Physiol. 1994;105(4):1295-1300.

45. Leeper FJ. Intermediate steps in biosynthesis of chlorophylls. In: Scheer H editor. Chlorophylls. Boca Raton, FL: CRC Press; 1991. p. 407-431.

46. Richards WR. Biosynthesis of chlorophyll chromophores of pigmented thylakoid proteins. In: Sundqvist C, et al. editors. Pigment-Protein Complexes in Plastids:Synthesis and Assembly. San Diego, CA: Academic Press; 1992. p. 91-178.

47. Von Wettstein D, Gough S, Kannangara CG. Chlorophyll biosynthesis. Plant Cell. 1995;7(7):1039-1057.

48. Porra RJ. Recent progress in porphyrin and chlorophyll biosynthesis. Photochem Photobiol. 1997;65(3):492-516.

49. Tewari AK, Tripathi BC. Temperature-stress-induced impairment of chlorophyll biosynthetic reactions in cucumber and wheat. Plant Physiology. 1998;117(3):851-858.

50. Kosova K, Vitamvas P, Prasil IT, et al. Plant proteome changes under abiotic stress-Contribution of proteomics studies to understanding plant stress response. J Proteomics. 2011;74(8):1301-1322.

51. Duque AS, de Almeida AM, da Silva AB, et al. Abiotic stress responses in plants: Unravelling the complexity of genes and networks to survive. In:Vahdati K, et al. editors. Abiotic Stress-Plant Responses and Applications in Agriculture. Rijeka, Croatia: InTech; 2013. p. 3-23.

52. Schoffl F, Prandl R, Reindl A. Molecular responses to heat stress. In: Shinozaki K, et al. editors. Molecular Responses to Cold, Drought, Heat and Salt Stress in Higher Plants. RG Landes Co, Austin, TX, USA; 1999. p. 81-98.

53. Suzuki N, Miller G, Morales J, et al. Respiratory burst oxidases: The engines of ROS signaling. Curr Opin Plant Biol. 2011;14(6):691-699.

54. Suzuki N, Koussevitzky S, Mittler R, et al. ROS and redox signalling in the response of plants to abiotic stress. Plant Cell Environ. 2012;35(2):259-270

55. Pagamas P, Nawata E. Sensitive stages of fruit and seed development of chili pepper (Capsicum annuum L. var. Shishito) exposed to high-temperature stress. Sci Hort. 2008;117(1):21-25.

56. Asada K. Production and scavenging of reactive oxygen species in chloroplasts and their functions. Plant Physiol. 2006;141(2):391-396.

57. Soliman WS, Fujimori M, Tase K, et al. Oxidative stress and physiological damage under prolonged heat stress in C3 grass Lolium perenne. Grassland Sci. 2011;57(2):101-106.

58. Rodriguez M, Canales E, Borras-Hidalgo O. Molecular aspects of abiotic stress in plants. Biotechnol Appl. 2005;22:1-10.

59. Wang W, Vinocur B, Shoseyov O, et al. Role of plant heat-shock proteins and molecular chaperones in the abiotic stress response. Trends Plant Sci. 2004;9(5):244-252. 
60. Vinocur B, Altman A. Recent advances in engineering plant tolerance to abiotic stress:achievements and limitations. Curr Opin Biotechnol. 2005;16(2):123-132.

61. Chakraborty U, Pradhan D. High temperature-induced oxidative stress in Lens culinaris, role of antioxidants and amelioration of stress by chemical pre-treatments. J Plant Interact. 2011;6(1):43-52.

62. Almeselmani M, Deshmukh PS, Sairam RK, et al. Protective role of antioxidant enzymes under high temperature stress. Plant Sci. 2006;171(3):382-388.

63. Ahmad P, Prasad MNV. Environmental Adaptations and Stress Tolerance of Plants in the Era of Climate Change. New York, NY, USA: Springer; 2012. p. 297-324.

64. Hasanuzzaman M, Nahar K, Fujita M. Plant response to salt stress and role of exogenous protectants to mitigate salt-induced damages. In: Ahmad P, et al. editors. Ecophysiology and Responses of Plants under Salt Stress. New York, USA: Springer; 2013. p. 25-87.

65. Hasanuzzaman M, Hossain MA, Fujita M. Nitric oxide modulates antioxidant defense and the methylglyoxal detoxification system and reduces salinity-induced damage of wheat seedlings. Plant Biotechnol Rep. 2011;5(4):353-365.

66. Hasanuzzaman M, Hossain MA, Fujita M. Selenium-induced up-regulation of the antioxidant defense and methylglyoxal detoxification system reduces salinity-induced damage in rapeseed seedlings. Biol Trace Elem Res. 2011;143(3):1704-1721

67. Hasanuzzaman M, Fujita M. Selenium and plants health: the physiological role of selenium. In:Aomori C, et al. editors. Selenium:Sources, Functions and Health Effects. New York, NY, USA: Nova Science Publishers; 2012. p. 101-122.

68. Sakamoto A, Murata N. The role of glycine betaine in the protection of plants from stress: clues from transgenic plants. Plant Cell Environ. 2012;25(2):163-171.

69. Rasheed R, Wahid A, Farooq M, et al. Role of proline and glycine betaine pretreatments in improving heat tolerance of sprouting sugarcane (Saccharum sp.) buds. Plant Growth Regul. 2011;65(1):35-45.

70. Chhabra ML, Dhawan A, Sangwan N, et al. Phytohormones induced amelioration of high temperature stress in Brassica juncea (L.) Czern \& Coss. Proceedings of 16th Australian Research Assembly on Brassicas, Ballarat, Australia; 2009.

71. Chen P, Yu S, Zhan Y, et al. Effects of jasmonate acid on thermotolerance of grape seedlings. J Shihezi Univ (Nat. Sci.). 2006;24(1):87-91.

72. Mitra R, Bhatia CR. Bioenergetic cost of heat tolerance in wheat crop. Curr Sci. 2008;94(8):1049-1053.

73. Kusano T, Yamaguchi K, Berberich T, et al. Advances in polyamine research in 2007. J Plant Res. 2007;120(3):345-350.

74. Chang HC, Tang YC, Hayer-Hartl M, et al. SnapShot:Molecular chaperones, Part I. Cell. 2007;128(1):212.e1-212.e2.

75. Baniwal SK, Bharti K, Chan KY, et al. Heat stress response in plants:a complex game with chaperones and more than twenty heat stress transcription factors. J Bio sci. 2004;29(4):471-487.

76. Morrow G, Tanguay RM. Small heat shock protein expression and functions during development. Int J Biochem Cell Biol. 2012;44(10):16131621.

77. Bohnert HJ, Gong Q, Li P, et al. Unraveling abiotic stress tolerance mechanisms-Getting genomics going. Curr Opin Plant Biol. 2006;9(2):180-188.

78. Maestri E, Klueva N, Perrotta C, et al. Molecular genetics of heat tolerance and heat shock proteins in cereals. Plant Mol Biol. 2002;48(56):667-681
79. Schoffl F. The role of heat shock proteins in abiotic stress response and the development of plants. ZMBP, Allgemeine Genetik: Universitat Tubingen; 2005.

80. Burke JJ. Identification of genetic diversity and mutations in higher plant acquired thermotolerance. Physiol Plant. 2001;112(2):167-170.

81. Lindquist S, Craig EA. The heat-shock proteins. Annu Rev Genet. 1988;22:631-677.

82. Vierling E. The roles of heat shock proteins in plants. Annu Rev Plant Physiol Plant Mol Biol. 1991;42:579-620.

83. Wu C. Heat shock transcription factors:structure and regulation. Annu Rev Cell Dev Biol. 1995;11:441-469.

84. Nover L, Bharti K, Doring P, et al. Arabidopsis and the heat stress transcription factor world:how many heat stress transcription factors do we need? Cell Stress Chaperones. 2001;6(3):177-189.

85. Li C, Chen Q, Gao X, et al. AtHsfA2 modulates expression of stress responsive genes and enhances tolerance to heat and oxidative stress in Arabidopsis. Sci China C Life Sci. 2005;48(6):540-550

86. Schramm F, Ganguli A, Kiehlmann E, et al. The heat stress transcription factor $H_{s f A 2}$ serves as a regulatory amplifier of a subset of genes in the heat stress response in Arabidopsis. Plant Mol Biol. 2006;60(5):759772 .

87. Busch W, Wunderlich M, Schoffl F. Identification of novel heat shock factor-dependent genes and biochemical pathways in Arabidopsis thaliana. Plant J. 2005;41(1):1-14.

88. Aprile A, Mastrangelo AM, De Leonardis AM, et al. Transcriptional profiling in response to terminal drought stress reveals differential responses along the wheat genome. BMC Genomics. 2009;10:279.

89. Hasanuzzaman M, Nahar K, Fujita M, et al. Enhancing plant productivity under salt stress - relevance of poly-omics. In: Ahmad P, et al. editors. Salt Stress in Plants:Omics, Signaling and Responses. Berlin, Germany: Springer; 2013. p. 113-156.

90. Chinnusamy V, Zhu J, Zhou T, et al. Small RNAs: Big role in abiotic stress tolerance of plants. Advances in Molecular Breeding toward Drought and Salt Tolerant Crops. Dordrecht, The Netherland: Springer; 2007. p. $223-260$.

91. Yeh CH, Kaplinsky NJ, Hu C, et al. Some like it hot, some like it warm:Phenotyping to explore thermotolerance diversity. Plant Sci. 2012;195:10-23

92. Liu HC, Liao HY, Charng YY. The role of class A1 heat shock factors (HSFA1s) in response to heat and other stresses in Arabidopsis. Plant Cell Environ. 2011;34(5):738-751.

93. Penueli L, Liang H, Rozenberg M, et al. Growth suppression, altered stomatal responses, and augmented induction of heat shock proteins in cytosolic ascorbate peroxidase (Apx1)-deficientArabidopsis plants. Plant J. 2003;34(2):187-203.

94. Stephenson LA. Germany's an of Monsanto's genetically modified maize (MON810):A violation of international law. Trade L Dev. 2010;2(2):292-328.

95. Semenov MA, Shewry PR. Modelling predicts that heat stress, not drought, will increase vulnerability of wheat in Europe. Sci Rep. 2011;1:66.

96. Porter JR, Semenov MA. Crop responses to climatic variation. Philos Trans R Soc Lond B Biol Sci. 2005;360(1463):2021-2035.

97. Schlenkera W, Roberts MJ. Nonlinear temperature effects indicate severe damages to U.S. crop yields under climate change. Proc Natl Acad Sci US A. 2009;106(37):15594-15598. 
98. Sinclair TR, Jamieson PD. Grain number, wheat yield, and bottling beer:An analysis. Field Crops Res. 2006;98(1):60-67.

99. Mitchell RAC, Mitchell VJ, Driscoll SP, et al. Effects of increased CO concentration and temperature on growth and yield of winter-wheat at 2 levels of nitrogen application. Plant Cell Environ. 1993;16(5):521-529.
100. Wheeler TR, Hong TD, Ellis RH, et al. The duration and rate of grain growth, and harvest index, of wheat (Triticum aestivum L.) in response to temperature and $\mathrm{CO}_{2}$. J Exp Bot. 1996;47(298):623-630. 